\title{
Oil Price Shocks and Their Effects on Mozambican Economy
}

\author{
Ibraimo Hassane Mussagy \\ Catholic University of Mozambique, Faculty of Economic and Managemnet-Beira \\ MusibauAdetunji Babatunde \\ Department of Economics, University of Ibadan, Nigeria
}

\begin{abstract}
In this paper, the oil price shocks and their effects on Mozambican economy is empirically analyzed for the time span covered by 1996:Q1-2012:Q4. The VAR methodology was used and the variables were Real Gross Domestic Product, Wages and Consumer Price Index. The results of the estimations, show a depressive impact on gross domestic product, increase in general the price level and the impact of an oil shock on wages is small and positive, in contradiction to conventional theory. In general, the wages decreases by an average of 1.5 percentage points. The key policy response to the impact of high oil prices is the extent to which governments have passed on the price increases to consumers, or have moderated them with subsidies, tax reductions, or pressure on oil companies to hold down price.
\end{abstract}

Keywords: Oil prices, Mozambique, Vector Auto Regression.

DOI: $10.7176 / \mathrm{JESD} / 11-4-11$

Publication date: February $29^{\text {th }} 2020$

\section{Introduction}

Since the 1970s, and at least until recently, macroeconomists have viewed changes in the price of oil as an important source of economic fluctuations in several developed and developing countries. The shocks observed in the mid 1970s have created high unemployment, and high inflation that characterized most industrialized economies (Blanchard and Gali, 2007).

The same effects observed in the 1970s were observed in the past decade. Since the late 1990s, the global economy has experienced two oil shocks of a magnitude comparable to those of the 1970s but, in contrast with the latter episodes, GDP growth and inflation have remained relatively stable in much of the industrialized world. These events, however, seem to call into question the relevance of oil price changes as a significant source of economic fluctuations.

The evolution of the price of oil since 1996 is displayed in Figure 1. More specifically, it shows the quarterly average price of a barrel from 1996:Q1-2012:Q4. The figure shows an increasing trend on the oil prices episodes.

The nineties were marked by the Gulf War. This moment made a series of oil price approaching 30 USD at the beginning of 1990. In this sequence, in the last quarter of 1998, economic growth decreased and pushed down the demand for oil and therefore reduced oil price to approximately 20 USD per barrel. In general, during the 80s until mid 2003, the price of oil was characterized by a certain oil price stability that fell within a price range between 10 and 30 USD per barrel.

In 2003, the USA invaded Iraqi and the price of oil suddenly increased from 27 to 35 USD a barrel. Then the world economy presented a recovery at the end of 2003 and throughout the year 2004. The growth rate of the gross domestic product (GDP) in several regions of the world have increased. This period was also characterized by an oil prices due to increased global demand, especially in China and Asia. According to the AfDB (2005) high oil prices are attributable to a rise in global demand rather than to supply side factors. The price of oil increased to an almost 60 percent. This increasing trend continued until 2005 where the oil price increased to $\$ 50$ per barrel approximately $\$ 15$ per barrel higher than in the first quarter of 2004, and remained above this level for the rest of 2005 and 2006.

The year 2007 was characterized by a strong world economic growth driving growth in oil use, thus crude oil prices increased dramatically during this period. The oil prices climbed to 95 USD per barrel in the last quarter of 2007. This represents an increase of almost 40 USD per barrel. The decline in the value of the dollar against other currencies supports continued oil consumption growth in foreign countries. After 2007 the oil price continued to increase and decrease showing a volatile pattern. 
Figure 1: Evolution of Oil price shock

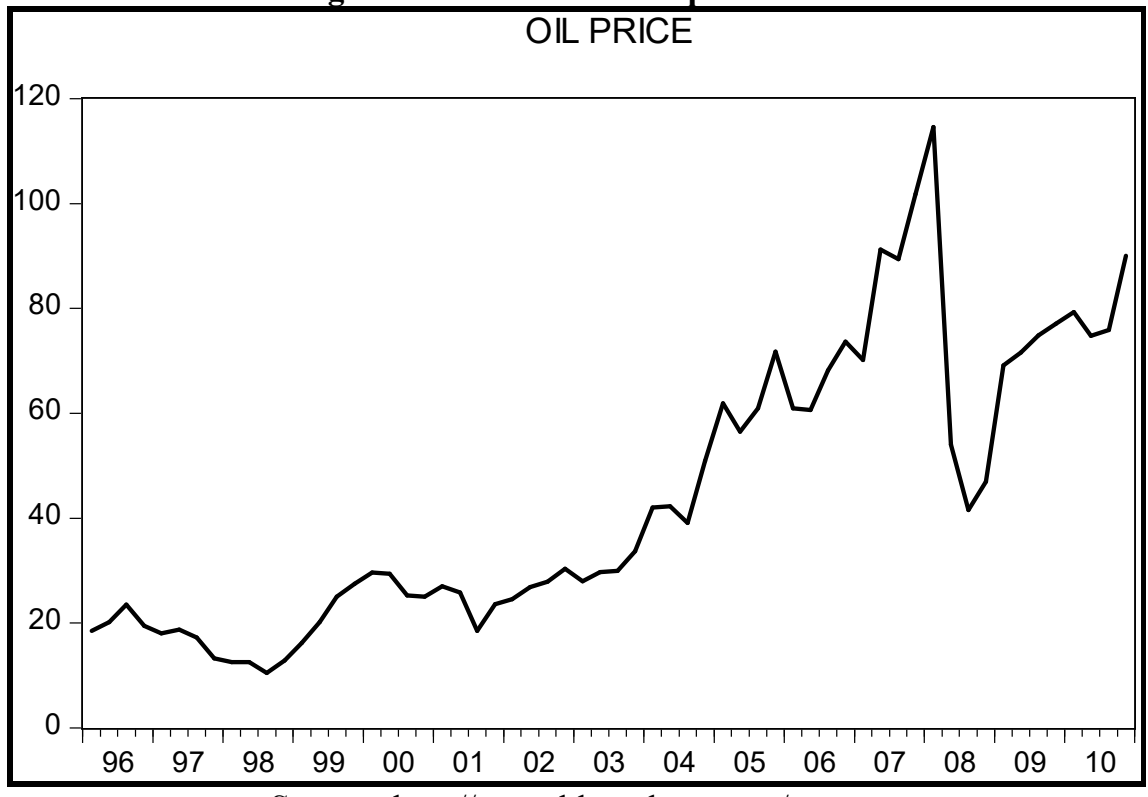

Source: http://www.bloomberg.com/energy

The impacts of international oil price changes is of interest to assess to what extent an oil price shock affects the economy. Chennai (2009) arguing in this line state that for many developing countries, the increase in oil prices over the last few years has made structural reform of the domestic petroleum pricing system a critical component of their macroeconomic policies. That is to say, the shock in the oil process, using the classical dichotomy, affects the nominal variables and the real variables.

In the case of Mozambique, few proportion of the existing research focused on oil price-macroeconomic relationships. Arndt and Matsinhe (2005) have provided and extensively analysed the oil process shock in the context of Mozambique.

The Mozambican economy is an imported oil economy which is affected by the fluctuations in the oil prices. In Mozambique oil and oil products represent an important part of total imports. According to MPD (2007) almost $20 \%$ of the total imports on the last 6 years are supported by the oil imports. In addition, the oil price has a relatively large financial burden on economy through direct and indirect effects.

This paper proposes to estimate the effects of oil price shocks on the Mozambican economy on a certain variables such as the real gross domestic product, consumer price index and the wages, relying on an unrestricted VAR model. One of the plausible hypothesis is that the effects of the increase in the price of oil have been bad for the Mozambican economy.

\section{Related Literature}

A large number of studies have investigated the macroeconomic impact of oil price shocks, focusing in particular on the response of economic growth and consumer price inflation. However, few of them have focused on African economies compared to other continents. However, specific studies have been conducted on the effects in Kenya, Nigeria, Mali, and Mozambique. Some of them are reviewed in this section.

Mork et al. (1994) and Bjornland (2000) demonstrated that oil price volatility has a positive impact on economic activity. In this sequence, Olamola (2006) have conducted a research with an objective to scrutinize the effect of oil price shock on output, inflation, the real exchange rate and the money supply in Nigeria. He used quarterly time series data from 1970:Q1-2003:Q3. The VAR methodology was used to undertake the analysis. The study concludes that oil price shock does not affect output and inflation in Nigeria. However, oil price shocks do significantly influence the real exchange rates.

Katsuya (2011) studied the macroeconomic effects of oil price changes in the Russian economy, one of the main oil producing nation in the world. The study employs the VAR model with time series data ranged from 1994:Q1-2009:Q3. The main conclusions were that a 1\% increase (decrease) in oil prices contributes to fluctuations on the exchange rate, which leads to a $0.46 \%$ GDP growth (decline).

In general there is a consensus with regard to net oil-exporting countries. Oil price volatility has a positive impact on the economic activities of the oil producing countries.

Dias (2012) has conducted a research to assess the effects of oil shocks on the Portuguese economy during the period 1984:Q1-2012:Q4. During the period of analysis three major oil price shocks occurred, defined as 
episodes where the accumulated changes in oil prices (in logs) exceeded 50 percent. The investigation relied upon the effect of selected variables such as the GDP, employment and inflation, using a structural VAR model. The results of the estimations predicted a depressing effect on the economic activity measured by the GDP in the long run. The profile of the effect on employment in the private sector is very similar, albeit somewhat smaller. As for the consumer prices, the results translate into higher inflation in the first two years subsequent to the shock. However this effect were temporary, as from the third year, the impact reduced slowly, with a virtually nil longterm effect on the price level.

A large number of studies have assessed the macroeconomic effects of oil price changes on the oil importing countries and on the oil exporting countries. Without reviewing them all, the empirical and theoretical findings presented previously generally found that oil price increases, the economy presents a contractionary effect on overall activity in net oil-importing countries through the supply-side and the exporting countries has a positive impact or a neutral impact on the economic activities of the oil producing countries.

This paper intends to estimate the effects of oil shocks on economic activity, inflation and wages for the Mozambican economy, relying on unrestrictive VAR model. For this purpose, we will closely follow the method used by Dias (2012). Not just because of this, but, most of the empirical results in this area were derived using VAR methodology.

\section{Methodology}

Most the empirical results in this area were derived relying on the vector auto regression methodology (VAR). The VAR is commonly used for forecasting systems of interrelated time series and for analyzing the dynamic impact of random disturbances on the system of variables. This is the methodology trail by Mork et al. (1994) and Bjornland (2000), Olamola (2006), Katsuya (2011) and Dias (2012). For this purpose, in this study we will follow this methodology. The analytical expressions is expressed by:

$$
X_{t}=\alpha+A \sum_{i=1}^{k} X_{t-1}+v_{t}
$$

Where: $\mathrm{X}$ are the endogenous variables vector, $\alpha$ is the equation constants vector, $\mathrm{A}$ is the coefficient vector, $v_{t}$ is the white-noise shocks vector and k VAR model's lag order.

- ADF Statistical Test and PP Test

The variables used in the study are nonstationary. The Augmented Dickey-Fuller (ADF) unit root tests and the Phillip Peron were applied in order to check and make sure that the dependent variable are stationary.

\section{- Lag Length Criteria}

The optimal lag length for the VAR model is reached based on information criteria, such as Akaike Information Criterion (AIC), Schwarz Criterion (SC) and Hannan-Quinn Criterion (HQ), which are generally adopted as measures of good fitness to the data.

$$
\begin{aligned}
& A I C=\ln \left|\sum \mu(p)\right|+\frac{2}{T}\left(N^{2} p\right) \\
& S C=\ln \left|\sum \mu(p)\right|+\frac{\ln T}{T}\left(N^{2} p\right) \\
& H Q=\ln \left|\sum \mu(p)\right|+\frac{2 \ln \ln T}{T}\left(N^{2} p\right)
\end{aligned}
$$

Where $\mathrm{T}$ is the sample size, $\sum \mu$ represents the estimated covariance, $\mathrm{N}$ is the number of parameters to be estimated and the lag chosen in order to minimize the criterion value.

\section{- Data and Sources}

For the estimation of the model a base sample covering the period 1996:Q1-2012Q4 was considered. The data we used were taken from the Mozambique National Institute of Statistics (INE) online at (www.ine.gov.mz) and the Index Mundi online at (http://www.bloomberg.com/energy).

The variables used are the Real Gross Domestic Product (RGDP), Consumer Price Index: (CPI), Oil prices (OIP) and Wages (W).

- Oil Prices (OIP): Crude oil prices measure the spot price of various barrels of oil, most commonly either the West Texas Intermediate or the Brent Blend. The OPEC ${ }^{4}$ basket price and the NMEX futures price are also sometimes quoted.

${ }^{4}$ OPEC stands for The Organization of Petroleum Exporting Countries. It is an organization of twelve oil-producing countries that control $61 \%$ of the world's oil exports and hold $80 \%$ of the world's proven oil reserves. OPEC's share of oil production declined in 2014 thanks to a 
- $\quad$ Real GDP (RGDP): a measure of aggregate output. The sum of quantities produced in an economy times their price in a base year. Also known as GDP in terms of goods or GDP in constant dollars (Blanchard, 2003).

- Consumer Price Index (CPI): the cost of a given list of goods and services consumed by a typical urban dweller (Blanchard, 2003).

- Wages (W): is cash payments expense for operating activities of the government in providing goods and services. It includes compensation of employees (such as wages and salaries), interest and subsidies, grants, social benefits, and other expenses such as rent and dividends.

\section{Empirical Results and Analysis \\ Unit Root Tests}

The Augmented Dickey Fuller (ADF) results in Table 1 reveal that oil price (OP), consumer price index (CPI), real output (GDP) and wage (W) are stationary at the first difference in the unit root model that included a constant and the model that included a constant and linear time trend. It can therefore be inferred that the variables are integrated of order one. In addition, the Phillips-Perron (PP) test confirmed the non-stationarity of the variables at their levels. Thus, we can safely conclude that the PP test supports the presence of unit roots in the series and the variables are integrated of order one.

Table 1: Augmented Dickey Fuller Test (ADF)

\begin{tabular}{|c|c|c|c|c|}
\hline Variables & \multicolumn{2}{l|}{ Levels } & First Difference \\
\hline & Model 1 & Model 2 & Model 1 & Model 2 \\
\hline Oil Price (OP) & -0.036027 & -1.630583 & $-5.587442 * * *$ & $-5.682618^{* * *}$ \\
\hline Consumer Price Index (CPI) & 0.259868 & -1.626414 & $-5.323743 * * *$ & $-5.287355^{* * *}$ \\
\hline Real output (GDP) & -6.483680 & -6.421188 & $-7.633622 * * *$ & $-7.547174 * * *$ \\
\hline Wage (W) & -1.209881 & -2.144636 & $-4.541888^{* * *}$ & $-4.493171^{* * *}$ \\
\hline
\end{tabular}

Note: The Null Hypothesis is the presence of unit root. Model 1 includes a constant while Model 2 includes a constant and a linear time trend. Lags were selected based on Schwarz Information Criterion. ***, ** and * denote significance level at $1 \%, 5 \%$ and $10 \%$ respectively.

Table 2: Phillips-Perron Test (PP)

\begin{tabular}{|l|c|c|c|c|}
\hline Variables & \multicolumn{2}{l|}{ Levels } & \multicolumn{2}{l|}{ First Difference } \\
\hline & Model 1 & Model 2 & Model 1 & Model 2 \\
\hline Oil Price (OP) & -0.268651 & -1.894642 & -5.595989 & -5.656760 \\
\hline Consumer Price Index (CPI) & 0.143201 & -1.624709 & -5.972411 & -5.925971 \\
\hline Real output (GDP) & -6.635860 & -6.591574 & -23.82867 & -25.51766 \\
\hline Wage (W) & -1.927857 & -2.229367 & -4.425579 & -4.357499 \\
\hline
\end{tabular}

*The Null Hypothesis is the presence of unit root. Model 1 includes a constant while Model 2 includes a constant and a linear time trend. The Bandwidth was chosen using Newey-West method with Barttlet Kernel spectral estimation. $* * *, * *$ and $*$ denote significance level at $1 \%, 5 \%$ and $10 \%$ respectively.

Since the variables are non-stationary at their levels, the analysis employed the Johansen test for cointegration using the trace and max-eigen value statistics and the auto-regressive distributed lad model (ARDL) for robustness. The Johansen cointegration test is valid when the series are non-stationary. However, we first determine the lag length of the estimation which must be small enough to allow estimation and high enough to ensure that errors are approximately white noise. The lag length selection procedure is based on five different information criteria: AIC, SIC, HQ, FPE and LR. Three out of the five information criteria in Table 3 conclude that the optimal lag length criteria for the oil price effect on the Mozambican economy is one. The consistency of the conclusions from three of the five set of information criteria is noteworthy due to the sensitivity of the Johansen procedure to lag length selection.

$16 \%$ increase in U.S. shale oil production. OPEC's share dropped from $44.5 \%$ in 2012 to $41.8 \%$ in 2014 . During this period, oil prices fell from \$108.54 in April 2012 to \$34.72 in December 2015 (http://useconomy.about.com/od/glossary/g/OPEC.htm) 
Table 3: VAR Lag Order Selection Criteria

\begin{tabular}{|c|c|c|c|c|c|c|}
\hline \multicolumn{6}{|l|}{ Endogenous variables: OP GDP CPI W } \\
\hline Lag & LogL & LR & FPE & AIC & SC & HQ \\
\hline 0 & 198.8758 & NA & $8.74 \mathrm{e}-10$ & -9.506136 & -9.338958 & -9.445259 \\
\hline 1 & 361.5685 & 285.7043 & $\mathbf{6 . 8 6 e - 1 3 *}$ & -16.66188 & $\mathbf{- 1 5 . 8 2 5 9 9 *}$ & $\mathbf{- 1 6 . 3 5 7 5 0 *}$ \\
\hline 2 & 370.5124 & 13.96109 & $9.91 \mathrm{e}-13$ & -16.31768 & -14.81308 & -15.76978 \\
\hline 3 & 393.7035 & $31.67574 *$ & $7.42 \mathrm{e}-13$ & $-16.66846^{*}$ & -14.49515 & -15.87706 \\
\hline * indicates lag order selected by the criterion \\
\hline LR: sequential modified LR test statistic (each test at 5\% level) \\
\hline
\end{tabular}

From the Johansen cointegration test results represented in Table 4, we found strong evidence of the cointegrating relationship in the oil price shocks model. In the test for the long run analysis, the trace and maxeigen statistics identify one cointegrating vector at the $5 \%$ critical level under the assumption of linear deterministic trend (Table 4). Therefore, the null hypothesis of no cointegration is rejected. This implies that oil price (OP), consumer price index (CPI), real output (GDP) and wages (W) are cointegrated. In addition, the ARDL test of cointegration was estimated for robustness check of the result. It showed that the computed F-statistic of 12.50 exceeded the lower and upper bounds critical values at the $1 \%, 2.5 \%, 5 \%$ and $10 \%$ significance level respectively (Table 5). Therefore, we can conclude that there is long run relationship between oil price (OP), consumer price index (CPI), real output (GDP) and wages (W).

Table 4: Unrestricted Cointegration Rank Test (Trace and Maximum Eigenvalue)

\begin{tabular}{|c|c|c|}
\hline & Trend assumption: Linear deterministic trend \\
\hline Hypothesized No. of CE(s) & Trace Statistic & Max-Eigen Statistic \\
\hline None & $52.24111^{*}$ & $30.97070^{*}$ \\
\hline At most 1 & 16.57550 & 11.58482 \\
\hline At most 2 & 4.990686 & 4.990686 \\
\hline & Trace test indicates 1 cointegrating equation(s) at the 5\% level \\
\cline { 2 - 3 } & Max-eigenvalue test indicates 1 cointegrating equation(s) at the 5\% level \\
\hline
\end{tabular}

Table 5: ARDL Bounds Test

\begin{tabular}{|l|c|c|l|l|}
\hline Test Statistic & Value & $\mathrm{k}$ & & \\
\hline F-statistic & 12.50671 & 3 & & \\
\hline Critical Value Bounds & $\mathrm{I}(1)$ Bound & & \\
\hline Significance & $\mathrm{I}(0)$ Bound & 3.77 & & \\
\hline $10 \%$ & 2.72 & 4.35 & & \\
\hline $5 \%$ & 3.23 & 4.89 & & \\
\hline $2.5 \%$ & 3.69 & 5.61 & & \\
\hline $1 \%$ & 4.29 & & \\
\hline
\end{tabular}

In order to put the study into context, we examine the response of the macroeconomic variables of real output (GDP), wages (W), and consumer price index (CPI) to oil price shocks. The first analysis examines the response of these variables on oil price while the send part of the analysis decomposes oil price into positive and negative oil shocks. This will enable us know whether there is symmetry in the way oil price shocks affect the Mozambican economy. Figure 1 presents the generalized impulse response of real output, CPI and wages. The depressive impact of oil price fluctuations on GDP is observed in the first 3 quarters. Thereafter, real output (GDP) witnesses increases over the next 7 quarters. The response patterns for CPI show a very similar trend. It starts with a decreasing effect from the first quarter but thereafter witnesses an increasing trend effect from the second quarter till the $9^{\text {th }}$ quarter. On the contrary, the depressive impact on wages is observed on the future 10 quarters which implies that oil price shock have a negative impact on wages in Mozambique. 


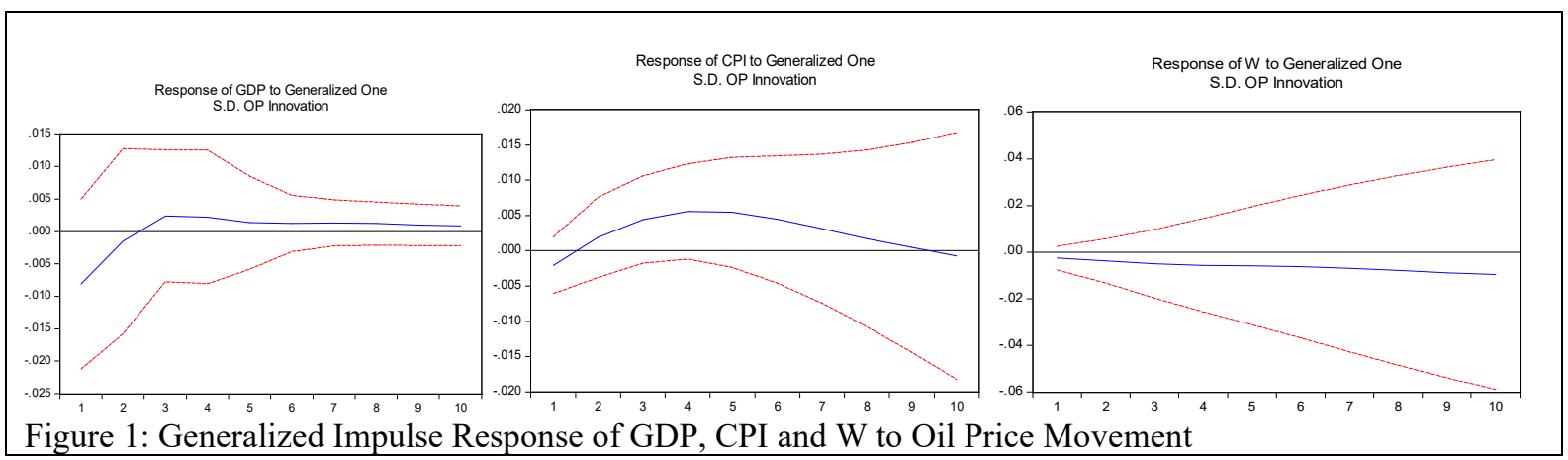

The positive oil price shock analysis revealed almost a similar effect for real output. The only difference is that real output was very low (close to zero) between the $5^{\text {th }}$ and $7^{\text {th }}$ period. The oscillating effect of positive oil price shocks was seen in its effect on CPI. The consumer price index witnessed increases in the $1^{\text {st }}$ to $3^{\text {rd }}$ quarter and also in the $5^{\text {th }}$ to $7^{\text {th }}$ quarter. The effect on wages shows a depressing effect between the $1^{\text {st }}$ and the $5^{\text {th }}$ quarter. Thereafter, wages continues to increase. The negative oil price shock effect is presented in Figure 3. There were initial negative responses for real output and consumer price index before they start getting close to zero around the $5^{\text {th }}$ and $6^{\text {th }}$ quarters respectively. There were positive and negative increases in wages but the positive effect stabilizes from the $6^{\text {th }}$ quarter. The upshot of the foregoing analysis is that the macroeconomic variables of wages, real output and consumer price index in Mozambique responds to oil price shocks differently and that there are significant responses of these variables to oil price shocks. In addition, it is clear that oil price shocks affects the variables differently.
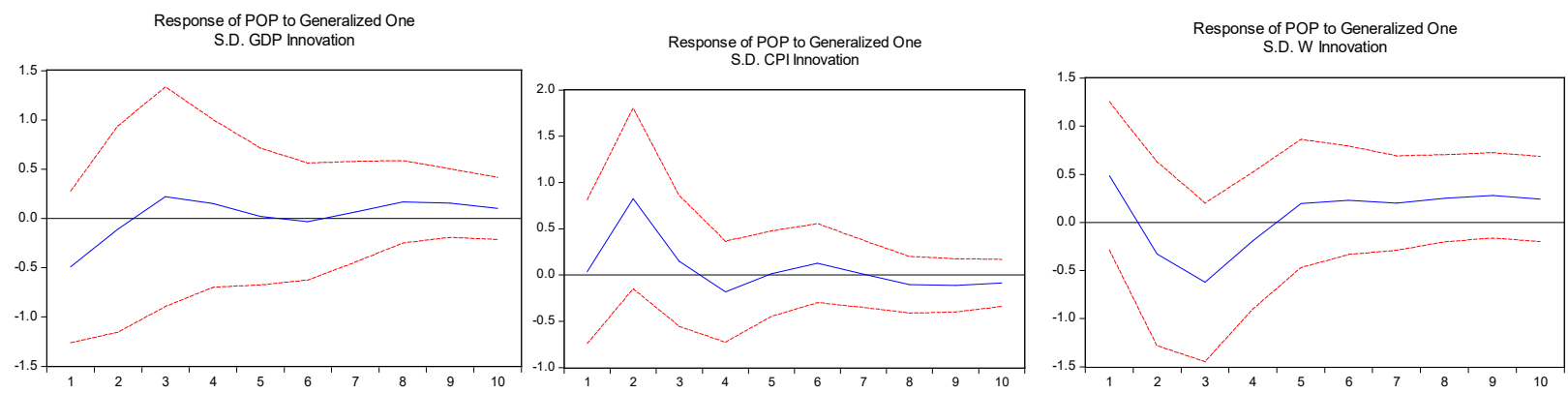

Figure 2: Generalized Impulse Response of GDP, CPI and W to Positive Oil Price Shock
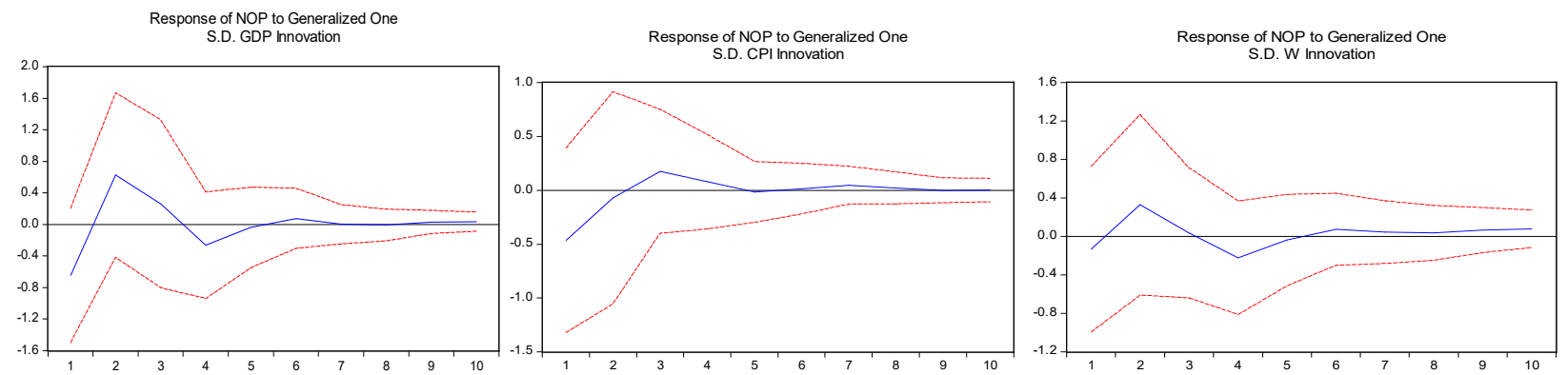

Figure 3: Generalized Impulse Response of GDP, CPI and W to Negative Oil Price Shock

Further, we decomposed oil price to the parts related to real output, wages, and consumer price index and oil price separately to know their relative importance in the oil price shocks model in Table 6. From Table 6, 96.21\% of the changes in GDP are due to the GDP itself while CPI and oil price explains only a paltry sum of $2.00 \%$ and $0.90 \%$ in the future changes of the GDP. Also, $87.24 \%$ and $8.12 \%$ of future changes in oil price are due to changes in oil price and consumer price index in the tenth period respectively. However, oil price changes explained about a quarter $(25 \%)$ of the future changes in the Mozambican wages in the tenth period while the largest future effect of $57 \%$ of future consumer prices is explained by oil price movement. It can be therefore presumed that while oil price has a significant impact on itself, real output and wages, the impact on the consumer price index is the largest. This implies that there is large pass through effect from oil price to consumer price index in Mozambique. 
Table 6: Variance Decomposition of Oil Price

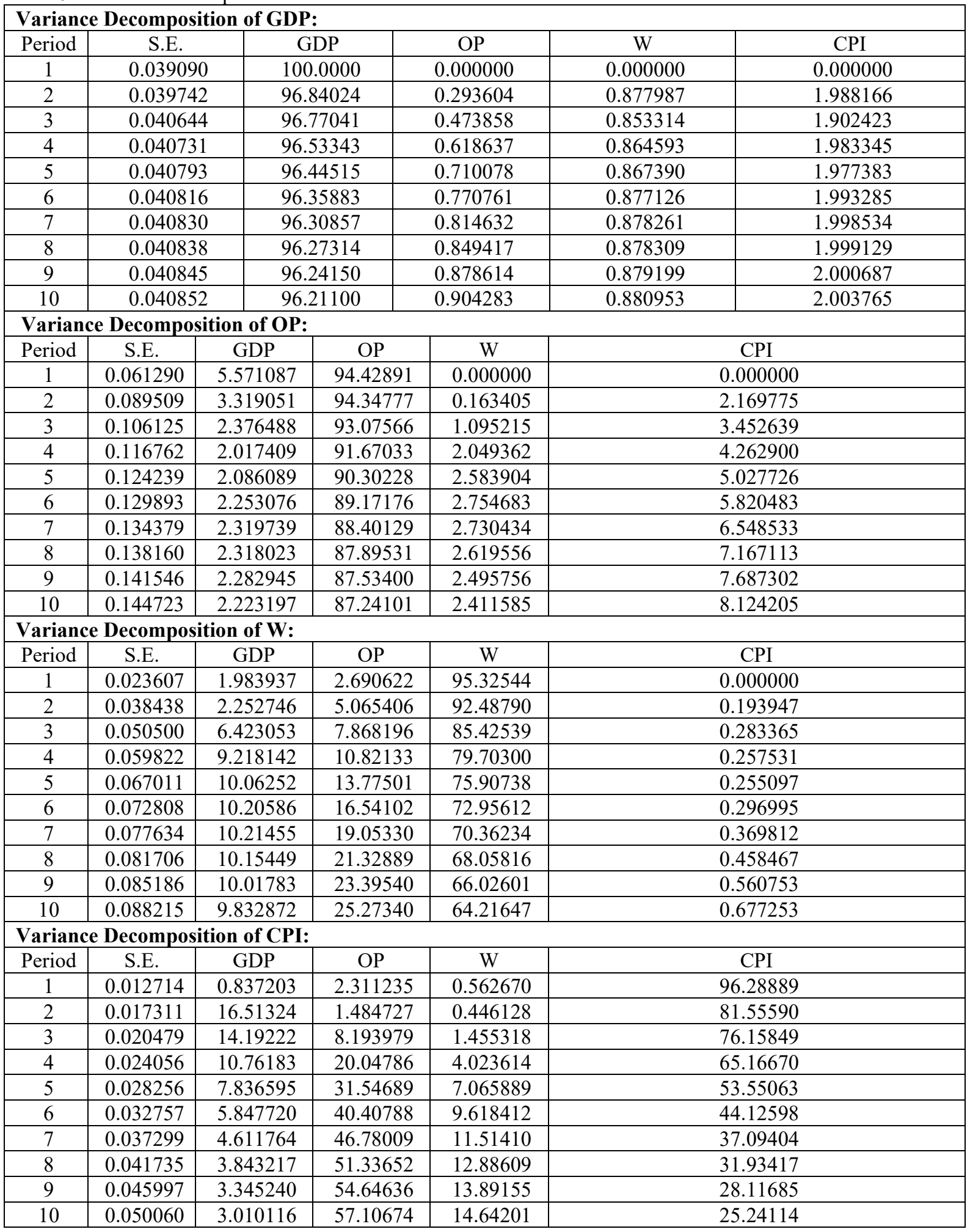

\section{Conclusions and Policy Implications}

In this paper, we have attempted to empirically investigate to what extent oil price increases affect the real real output (GDP), consumer price index (CPI) and wages (W) in Mozambique. The empirical results were derived using VAR methodology. The impulse responses functions follow, in general, the conventional pattern for the effects of oil shocks on overall activity and inflation-depressive on GDP and inflationary on prices. From the discussion, five conclusions clearly emerge from the analysis:

1. There is a long run relation between oil price, consumer price index, wages and real output in Mozambique. 
2. The depressive impact on GDP and consumer price index is observed in the early period while the negative impact is confirmed for the wages throughout the estimation period.

3. Positive oil price shocks have depressing effects on real output, consumer prices and wages in Mozambique.

4. Negative oil price shocks have increasing effects on real output, consumer prices and wages in Mozambique from the $5^{\text {th }}$ quarter when the effects will manifest.

5. Given the future large pass through effect from oil price to consumer price index in Mozambique, our estimates point to much larger effects of oil price shocks on inflation.

The empirical analyses have broadly corroborated these predictions. These results, besides establishing a fair approximation to the effects of oil shocks on Mozambican economy, they leave no doubt about the harmful effects of the oil price shocks on the Mozambican economy. The key policy response to the impact of high oil prices is the extent to which governments have passed on the price increases to consumers, or have moderated them with subsidies, tax reductions, or pressure on oil companies to hold down price.

\section{References}

- Aanye D. M. (2011). What is the Impact of Oil Price Change on Ghana's Economy? Energy Center

- Arndt, L. Matsinhe, P. Mulder, E. Paulo, J. E. Van Dunem (2005) "O Impacto do Aumento do Preço do Pétroleo na Economia Moçambicana”, DNEAP Discussion Paper 19P, MPD, Mozambique. http://www.mpd.gov.mz/gest/publicat.htm

- $\quad$ Blanchard, O. (2003). Macroeconomics. Third Edition. USA, Prentice Hall.

- Chennai (2009). Impact of High Oil Prices on African Economies. African Development Bank

- Dias F. C. (2012). Oil Price Shocks and Their Effects on Economic Activity and prices: an Application for Portugal. Banco Central

- Jiménez-Rodríguez, R. and Sánchez, M. (2012). Oil Price Shocks and Japanese Macroeconomic Developments. Department of Economics. University of Salamanca

- Latife, Ghalayini (2011).The Interaction between Oil Price and Economic Growth. Middle Eastern Finance and Economics.

- $\quad$ MPD (2007). O Impacto do alto preço do petróleo na economia Moçambicana. Notas. No1.

- Olivier J. Blanchard \& Jordi Gal (2007). The Macroeconomic Effects of Oil Price Shocks: Why are the 2000s so different from the 1970s? MIT and NBER.

- Philip A. O. (2006). Oil Price Shock and Aggregate Economic Activity in Nigeria. African Economic and Business Review Vol. 4 No. 2. 